\section{Cancer: Myths and Realities of Cause and Cure}

M L Kothari and L A Mehta

Marion Boyars, London \& Boston, 1979, pp 159, £2.50, paperback

This book is one in a series dealing with alternatives to industrial society. Called 'Ideas in Progress', the series includes books on a wide range of contemporary issues, particularly those relating to capitalism and conservation. In the present volume, current attitudes towards and ideas about the third big ' $C$ ' are brought under scrutiny. It is claimed that the book is iconoclastic, exploding the myths and exposing realities about cancer. To a certain extent this is so, but the tone of the book left this reviewer with the strong impression that, rather than being true cleansers of the temple, the authors have merely knocked down one set of images and replaced them by another.

The book contains many useful data. Of particular interest is the fact that the overall death rate from cancer is remarkably constant throughout the world. It is pointed out that although there is, for example, a high incidence of oropharyngeal carcinoma in India this is compensated by low rates for other cancers. The inference drawn from this and parallel data is that cancer is a herd phenomenon. It is a fact of life, and needs to be accepted as such in the same way as ageing. Because it is inevitable for a proportion of the population to develop cancer, there is no need for guilt in the heavy smoker who develops lung cancer or the happy lover who contracts cancer of uterine cervix. And before you can say 'Kothari and Mehta', epidemiological studies are dashed into pieces and the study of carcinogens trampled under foot. As cancer cannot be caused, it cannot be prevented (but could its onset be delayed ?); therefore adopt a que sera sera attitude.

It is perhaps not without significance that this book with its relatively fatalistic approach to life, disease and death, comes from the home of Hinduism. Yet it is reasonable that the overoptimistic "with a bit more effort/time/money' western oncologist should occasionally be given a full frontal exposure to what in places amounts to therapeutic nihilism. Is the one billion dollars spent annually on cancer research in the USA money well spent? It is not only the authors who express doubts about this. It is right that over enthusiastic surgeons should be restrained from extensive mutilating operations of limited benefit to the patient and clinical oncologists should be asked to think twice before recommending chemotherapy with equally devastating effects on the patient's joie de vivre. But to bolster one's plea with a quotation by a doctor who, in 32 years experience, has never seen a patient completely cured of cancer is overstating the case.

There is, however, much wisdom between overstatements, but I have the strong impression that the nonprofessional reader will end up with as frightening an image of cancer as he began with - the same devil but with a different selection of horns. To claim, on the basis of a herd phenomenon that cancer can be understood is naive, and to discourage treatment is to oversimplify. Moreover, to think that a mere recitation of the facts (as seen by the narrator) will cure people of their dread of cancer is to deny one aspect of our humanity. We all have an innate fear of death and, since time immemorial, man has focused his fears and anxieties on one disease or group of diseases. In the past, leprosy was prominent in this respect; now it is cancer. If cancer becomes 'acceptable', it will not remove man's fear of death; the mantle will, quite simply, be fitted round the shoulders of yet another disorder. ROBERT TWYCROSS

\section{Terminal Care}

Derek Doyle (Ed).

Churchill Livingstone. 70 pages unpriced. 1979

\section{Dilemmas of Dying}

Ian E Thompson (Ed) Edinburgh University Press pages, $£ 4 \cdot 00,1979$

These two books are complement although there is some overlap.

The Conference Report editedithy Dr Doyle is shorter and more specifically informative about the iss $\vec{e}$ es and problems of managing terminally ill patients. It is a helpfully edifed summary of the papers given at. a remarkably well attended mudtidisciplinary Conference held Sin Edinburgh. Ian Thompson has Pad a harder job in editing the opinions and discussions of a group work周g in this field, who met over a two year period. As the study group's charman, David Edge, puts it, the group had to face the conflicts inherentin caring for dying people, as welças agreeing on the many areas of consensus. The group's main plea is for more education about these issters. This plea is aimed mainly at those who decide on, and provide 胥e input for, the medical students' curriculum. The discussions were sponsored by the multidisciplinary Edinburgh Medical Group, so they also, quite properly, point out that these subjects are not the prerogatove of doctors and should be in the undergraduate and ongoing educational curricula of all caring professions.

The Terminal Care Conferemce was chaired by the Director of the London Institute of Cancer Reseafsh and the chapters are by a professor of geriatric medicine, two doctor fin charge of hospices, a senior socm worker with considerable experiefice in terminal care, a psychiatrist with a special interest in grief and bereafement, the director of a nursing reseafech unit, a theologian and a GP. The editor has also included a small, gut important, amount of the discussion.

Most, if not all, of the practipal problems and ethical dilemmas encountered in the managementof patients dying from cancer are also seen in those with chronic and sevfre non-malignant illnesses. This is 
recognised in many of the discussions in Dilemmas of Dying as well as in Professor Williamson's contribution to Terminal Care. Death is increasingly a problem of older rather than younger people, and it is occurring increasingly in hospital. Distressing and difficult problems include depression, decisions about acting or not acting (how many tests to order, when to give antibiotics or put up drips) financial difficulties, and support of the bereaved. All of these may be more important than radiotherapy, surgery or pain relief, so often seen as important aspects in the palliative care of patients with malignant disease. Ill elderly people often have many other problems requiring expert management in addition to their lethal illness, and may be supported less well by relatives and friends than younger patients - or have no social support.

Death in old age is often expected and may be accepted as inevitable, but still requires skilful management. Depression and even suicide, are common and the bereaved - spouses, children and friends - may not be able to accept death and need help with their suffering. These problems and the ethical problems of management discussed in Dilemmas of Dying are seen just as much in old people dying from incurable nonmalignant diseases as in those with cancer. Professor Williamson suggests we should manage the situation as if the patient were a relative, we should try and judge whether the patient would thank us for what we are doing (or for not doing something), and we should make every effort to clarify what the objectives of any treatment are.

These issues should be faced, even in the very confused patient. In all these situations other members of the team must be consulted, especially the nurses.

Other contributions to Terminal Care crystalise and consolidate experience in the management of people with cancer, in hospices and at home. Home care schemes, as described by Dr Doyle, are an obvious extension of hospice work. They provide advice and support for GP's nurses and social workers as well as for 'patients and relatives'. Dr Donald, a GP, contends that the difficulty of balancing science and caring, which is central in the management of the dying, is best tackled by the primary care team. He feels that most of the problems are seen in people who are not in hospitals or hospices, and that these are usually best dealt with at home. Although so many people now die in hospital, a large number still die at home, and many of these have cancer. Even when death takes place in hospital, it is often only as the terminal event in a terminal illness which has been largely managed at home. Dr Doyle had found that terminal patients, dying at home, had even more pain, breathlessness and constipation than those studied by Cartwright and her colleagues.

Dr Donald also reminds us how poor doctor-nurse communication tends to be. Lisbeth Hockey believes the nurse occupies the central position in the management of dying people, and that the nurse has two specific roles - care and consideration. She comments, yet again, how little nursing research there has been in this field. Dr Hillier makes the same point in relation to the miniscule level of spending on research into cancer pain. Like all the contributors he makes practical points as well as discussing operational and management problems; virtually, all patients receiving opiates will have a constipation problem.

The priest and psychiatrist fulfil several roles, as is obvious from the contributions in both books. They describe and explain the actual behaviour of dying people, and of the bereaved. They can help the patient and survivors, and the carers. They can highlight the dilemmas of managing the dying and in helping others to clarify their thoughts and make decisions easier. The minister and doctors are no longer the only confessors, all members of the team may have to take on this role.

This review has referred mainly to Terminal Care. It is much more difficult to review a book based on group discussions on problems with many moral and philosophical, as well as practical, aspects. Nevertheless many similar issues are explored the work of the nurse, and of the GP, what to do with older patients and the medical aspects of bereavement (eg increased morbidity and mortality). The dangers of overemphasising the medicalisation of bereavement are stressed. The editor has also included helpful lists of additional suggested reading and appendices. These summarise important discussions, such as what to teach, what to tell (patients), the role of the nurse, how to improve communications, and an interesting section on the minister's role, and on the conduct of funerals. Details are given of some of the specific problems of arranging funerals, and of the views of bereavement counselling groups such as Cruse.

Important points about money are made in both books. Death Grants are hopelessly inadequate. The present financial climate is likely to adversely affect the NHS provisions for supporting existing hospices and home care schemes, let alone for creating any new ones. However much the impetus in the past for improving the care of the dying has come from individuals and religious groups and money come from voluntary fund-raising, the prime responsibility for providing care for ill people, and help for other relatives and for educating the carers, must lie with the NHS.

The two main difficulties, as we all know, are how to get the subject of terminal care into the curriculum, and how to persuade the student that it is attractive - or at least important, alongside preventive, curative, epidemiological medicine and so on. In respect of the curriculum one hopes that it is increasingly being included, in psychiatry, in geriatric and thoracic medicine, in oncology and clinical pharmacology and in surgery. However, the real problem is to arrange sufficient expert and coordinated teaching about the management of dying patients.

Perhaps the breakthrough will only come when we have a professor of terminal care and obligatory examination questions on the subject! Until then the gaps can be helped by recommending these two books, one for information about the more simple practical aspects of terminal care and examples of team-work in and out of hospital, the other to help highlight the very real problems faced by those caring for dying people. They do not cover all the problems, and students would also benefit from other teaching, such as Anne Cartwright's Life Before Death, and Management of Terminal Illness, edired by Cicely Saunders.

Few qualified doctors (and nurses, social workers and others) have had any training in the care of the dying, or any opportunity to discuss the management problems and ethical dilemmas involved. They will also be helped by reading these books.

MICHAEL F GREEN 